\title{
Hall-Riggs syndrome
}

INSERM

\section{Source}

INSERM. (1999). Orphanet: an online rare disease and orphan drug data base. Hall-Rigg S syndrome. ORPHA:2107

Hall-Riggs syndrome is a very rare syndrome consisting of microcephaly with facial dysmorphism, spondylometaepiphyseal dysplasia and severe intellectual deficit. 